\title{
Effects of Deep Abdominal Muscle Strengthening Exercises on Pulmonary Function and the Ability to Balance in Stroke Patients
}

\author{
Jeong-II Kang', Beom-Ryong Kim², Seung-Kyu Park', Dae-Jung Yang', Dae-Keun Jeong', Je-Ho Kim \\ 'Department of Physical Therapy, Sehan University; ${ }^{2}$ Department of Physical Therapy, Graduate School of Sehan University, Yeongam-gun, \\ Jeollanam-do, Korea
}

Purpose: This study investigated effects of deep abdominal muscle strengthening exercises on pulmonary function and the ability to balance in stroke patients and was conducted to propose an exercise program for improving cardiovascular function.

Methods: Study subjects were 20 patients with hemiplegia due to stroke, who were divided into the deep abdominal muscle strengthening exercise group (experimental group), 10, and the control group, 10. Pulmonary function tests measured FVC and FEV1, dynamic balance ability was measured using TUG. Static and dynamic balance ability was measured using BBS. The experimental group performed exercises during a period of 6 weeks, 5 times a week for 40 minutes, whereas the control group did not participate in regular exercise. The difference before and after the exercise was compared using paired t-test, difference in exercise before and after between groups was ANCOVA and level of significance was set at $\alpha=0.05$.

Results: The changes in FVC and FEV1 within the group showed a significant difference only in the experimental group $(p<0.001)$ $(p<0.01)$, between-group difference was statistically significant only in FVC and FEV1 changes in the experimental group $(p<0.001)$. The TUG changes within the group showed a significant difference in the experimental group and control group $(p<0.001)(p<0.05)$, while BBS changes showed a significant difference only in the experimental group. Between-group difference was statistically significant only in TUG and BBS changes in the experimental group. The experimental group showed a more effective significant difference than the control group $(p<0.001)$.

Conclusion: Can exercise involving a deep abdominal muscle strengthening program be applied in patients with stroke with difficulty in control of trunk and decreased breathing ability?

Keywords: Balance, Deep abdominal muscle strengthening exercises, Pulmonary function, Stroke

\section{서 론}

뇌졸중은 뇌혈관의 문제로 뇌에 혈류공급이 부족하여 편마비, 감각 이상, 근력저하와 근지구력의 감소 및 운동장애와 같은 신경학적 기 능장애를 유발하며, 운동조절 능력의 저하로 인해 일상생활동작의 감소와 균형 및 상호조절에 장애를 가져온다. ${ }^{1}$ 그리고 뇌졸중으로 인 한 편마비 환자들은 가슴우리와 몸통의 비대칭성과 비정상적인 정 렬로 호흡 및 폐 기능을 저하시키며, 직접 또는 간접적으로 호흡근육 의 운동성이 감소되면서 호흡근육의 근력저하와 지구력의 감소로 호흡주기에 변화를 가져온다. ${ }^{2}$ 이와 같은 어려움을 호소하는 뇌졸중 환자에게 일반적인 운동치료는 일상생활동작과 보행속도를 향상 시
킬 수는 있지만, 폐 기능 회복과 증진의 효과는 제한적이며, 아급성 뇌졸중환자가 만성으로 진행됨에 있어 폐 기능의 회복과 증진의 효 과가 없기 때문에, 호흡 훈련을 통한 호흡근육의 근력향상과 지속적 인 관리가 필요한 실정이다.3.4

정상적인 호흡은 가슴우리(thoracic cage)가 확장 또는 축소되어 공 기가 안과 밖으로 이동하는 것으로 들숨(inspiration)과 날숨(expiration)으로 나눠지며, 들숨은 폐의 압력이 대기압 이하로 감소되었을 때 발생하고, 날숨은 폐의 압력이 대기압을 초과했을 때 발생한다. 들 숨은 능동적 과정으로 들숨근육(inspiratory muscle)의 능동적 수축 을 통해 가슴우리가 확장되어 가슴 안(thoracic cavity) 용적이 증가하 는 것으로, 이때 관여하는 들숨근육은 가로막(diaphragm)과 바깥갈
Received Jul 23, 2015 Revised Aug 11, 2015

Accepted Aug 16, 2015

Corresponding author Beom-Ryong Kim

E-mail kimbr21@hanmail.net
Copylight (C2015 The Korea Society of Physical Therapy

This is an Open Access article distribute under the terms of the Creative Commons Attribution Non-commercial License (Http:// creativecommons.org/license/by-nc/3.o.) which permits unrestricted non-commercial use, distribution, and reproduction in any medium, provided the original work is properly cited. 
비사이근(external intercostal muscle)이 있고, 노력성 들숨근육은 목빗 근(sternocleidomastoid muscle), 목갈비근(scalene muscle), 등세모근 (trapezius muscle), 큰가슴근(pectoralis major muscle), 작은가슴근(pectoralis minor muscle), 앞톱니근(serratus anterior muscle), 척주세움근 (erector spinae muscle)이 있다. 날숨은 수동적 과정으로 들숨근육의 이완을 통해 날숨근육(expiratory muscle) 관여 없이 가슴우리가 제자 리로 되돌아가는 과정이다. 보조적인 노력성 날숨근육은 배곧은근 (rectus abdominis muscle), 배바깥빗근(external oblique abdominal muscle), 배속빗근(internal oblique abdominal muscle), 배가로근(transverse abdominal muscle), 속갈비사이근(internal intercostal muscle)이 있다. ${ }^{5}$ 그러나 이들 복부의 근육과 몸통의 근육들은 몸통의 안정성과 운동 성 및 자세조절에 대한 중요성 때문에 ${ }^{6}$ 대부분 몸통 안정화 운동이 뇌졸중 환자들의 균형능력에 미치는 영향에 대한 선행연구들이 대 부분으로, Chae와 Lee는 시각적 피드백을 이용한 척추 안정화 운동 이 만성 뇌졸중 환자들의 균형능력과 보행능력 향상에 효과적이라 고 하였으며, Seo 등은 초음파를 이용한 체간 안정화 운동이 복부근 육의 두께 변화에 향상을 보였고, 정적균형과 동적균형능력 향상에 영향을 미친다고 하였다. 이처럼 일반적으로 선행연구들은 복부근육 과 관련하여 균형능력, 보행능력, 복부 심부근육 두께에 관한 연구가 주를 이루고 있는 반면, 호흡근육으로써 복부 근육 강화 운동이 폐 기능 향상에 따른 효과 검정에 대한 연구가 필요한 실정이다.

체간안정화 운동으로 호흡근육으로 효과를 검토한 일부 연구를 살펴보면, $\mathrm{Choi}^{9}$ 는 만성 뇌졸중 환자들을 대상으로 체간 안정화 운 동을 6주간 실시한 결과 복부 심부근육 두께와 폐 기능에 향상을 보 여, 날숨근육과 관련된 복부 심부근육 훈련이 필요하며, Yoon ${ }^{10}$ 은 뇌 졸중 환자를 대상으로 8 주간 코어 운동프로그램을 실시한 결과 들 숨능력 향상에 효과가 있어, 다른 호흡 프로그램들과 병행하여 대상 자의 호흡기능을 향상하는 데 노력해야 한다. 그리고 Jung 등1ㅗ또한 뇌졸중 환자를 대상으로 4주간 앉은 자세에서 들숨근육 트레이닝과 병행하여 복부근육에 전기자극한 결과 폐 기능이 향상됨을 알 수 있 었는데, 호흡근육으로서의 복부근육에 관한 연구가 진행 중에 있으 나 복부근육 중 심부근육에 어떠한 영향을 미치는지에 대한 연구 또 한 필요한 시점이다. 본 연구는 6주간의 복부 심부근육 강화운동이 뇌졸중 환자의 폐 기능 및 균형능력에 미치는 영향에 대한 복부 심부 근육이 호흡근육으로써 역할을 규명하고자 몸통 및 호흡근육 특히 복부근육의 약화로 근 긴장도를 감소시켜 호흡능력 저하와 몸통조 절의 어려움을 겪는 뇌졸중 환자를 대상으로 복부 심부근육 강화 운동을 실시하여 운동 전후 폐 기능 및 균형능력의 변화를 알아보 고, 뇌졸중 환자의 효과적인 운동방법을 제공하는 데 연구의 목적이 있다.

\section{연구방법}

\section{1. 연구대상}

본 연구는 2014년 11월부터 12월까지 6주 동안 J시 소재 D병원 내원환 자를 대상으로 실시하였다. 대상자는 뇌졸중으로 인한 편마비를 진 단받고, 1 년 이상 3 년 미만 경과한 자로, 폐 질환 혹은 선천적 가슴우리 의 변형이나갈비뼈 골절 등의 병력이 없는 자, 독립적으로 $10 \mathrm{~m}$ 보행 이 가능하며, 5-60 초안에 보행할 수 있는 자, 연구자가 지시하는 내용 을 이해하고 따를 수 있는지 여부를 판별하는 간이 정신상태 검사 (Mini mental state examination-Korea, MMSE-K) 점수가 24점 이상인 자 를 대상으로, 연구에 대한 근본 목적의 설명을 통해서 동의서를 받은 20 명을 대상으로 일반적 물리치료와 복부 심부근육 강화운동을 실 시한 실험군 $(\mathrm{n}=10)$ 과 일반적 물리치료를 실시한 대조군 $(\mathrm{n}=10)$ 으로 무작위 배정하였다. 연구대상자 일반적 특성은 다음과 같다(Table 1).

\section{2. 실험방법}

\section{1) 복부 심부근육 강화 운동 프로그램}

실험군은 일반적 운동치료 30 분, $\mathrm{McGill}^{12}$ 에 브레이싱 운동(bracing exercise) 30 분으로 구성 주 5회 6주간으로 시행하였다. 복부 심부근 육 강화 운동의 방법은 대상자가 무릎을 90 도 구부리고 누운 자세로 허리와 골반의 정렬을 맞춘 상태에서 생체 피드백 장치를 허리부에 위치시킨 후 압력계로 $40 \mathrm{mmHg}$ 의 압력을 유지시켰다. 이후 누군가 가 주먹으로 복부를 내리치려고 할 때 복부에 힘이 자동적으로 들어 가는 것처럼 복부를 가격 당한다고 생각하고 복부에 힘을 주어 복부 심부근육이 수축하도록 하여 압력계의 압력을 $70 \mathrm{mmHg}$ 로 상승시 켜서 유지하도록 하였다. 이때 몸통의 근육들이 밖으로 퍼져나간다 는 느낌으로 시행시켰으며 배곧은근이 볼록해지거나 들어가면 안 되며, 힘을 너무 많이 줘서 날숨이 힘들면 안 되고 편하게 쉴 수 있어

Table 1. Characteristics of subjects

$(n=20)$

\begin{tabular}{llccc}
\hline & & $\begin{array}{c}\text { Experimental } \\
(\mathrm{n}=10)\end{array}$ & $\begin{array}{c}\text { Control } \\
(\mathrm{n}=10)\end{array}$ & $\mathrm{p}$ \\
\hline Sex & Male & $6(30 \%)$ & $5(25 \%)$ & \\
& Female & $4(20 \%)$ & $5(25 \%)$ & \\
Age (year) & & $6.1 \pm 6.5$ & $6.0 \pm 7.0$ & 0.242 \\
Height (cm) & & $1.6 \pm 7.8$ & $1.6 \pm 1.1$ & 0.842 \\
Weight (kg) & & $6.7 \pm 5.3$ & $6.3 \pm 7.9$ & 0.959 \\
Affected side & Right & $8(40 \%)$ & $6(30 \%)$ & \\
& left & $2(10 \%)$ & $4(20 \%)$ & \\
Onset type & Infarction & $9(45 \%)$ & $7(35 \%)$ & \\
& Hemorrhage & $1(5 \%)$ & $3(15 \%)$ & \\
Onset time after stroke (day) & $1.8 \pm 6.8$ & $1.7 \pm 3.4$ & 0.074 \\
MMSE-K (score) & $2.6 \pm 2.2$ & $2.6 \pm 2.3$ & 0.192 \\
\hline
\end{tabular}

Values are presented as mean \pm standard deviation. 
야 한다. ${ }^{13}$ 대상자가 스스로 복부 압력을 가하면 연구자가 운동이 정 확하게 실시되고 있는지 feedback을 주면서 6주 동안 운동조절(motor control)의 변화를 확인하여 5 초, 10 초, 15 초, 20 초로 ${ }^{14}$ 점진적으로 유 지시간을 늘려갔다.

\section{2) 일반적 운동치료 프로그램}

일반적 운동치료는 30 분, 하루 2 회로 구성 주 5 회 6 주간 시행하였다. 매트운동, 보행운동, 중추신경계발달치료를 환자수준에 맞게 운동 강도를 조절하여 10 분씩 실시하였다. 몸통조절능력을 높이기 위해 몸통 안정성 운동에 초점을 맞췄으며, 몸통의 유연성을 위한 신장운 동을 포함하였다.

\section{3) 측정항목 및 방법}

(1) 폐 기능 검사

폐 기능 검사(pulmonary function)는 SCHILLER SP-260 (PC-Spirometry, SP-1, Medical Supply Co., Ltd, Switzerland)을 사용하였다. 측정방법 은 대상자에게 검사방법에 대한 충분한 설명과 시범을 통하여 교육 이 이루어진 상태에서 실시하였다. 측정 지표는 최대 노력성 날숨에 서 얻어진 노력성 폐활량(forced vital capacity, FVC)과 최대 노력성 날 숨을 시작한 후 1 초간 내신 1초간 노력성 날숨량(forced expiratory volume at one second, FEV1)을 측정하였다. 폐 기능 검사는 앉은 자세에 서 3회 반복 측정하여 평균값을 기록하였다.

\section{(2) 동적균형 능력 검사}

일어나 걷기 검사(Timed up and go test, TUG)는 운동성과 균형을 빠 르게 측정할 수 있는 검사도구로 측정자 내 신뢰도는 $r=0.99$ 이고, 측 정자간 신뢰도는 $r=0.98$ 로 신뢰할만한 도구이다. 대상자는 평편한 바닥에 $46 \mathrm{~cm}$ 높이의 팔걸이가 있는 의자에 편안하게 앉은 상태에서 “시작"이라는 신호와 함께 의자에서 일어나서 의자에서 $3 \mathrm{~m}$ 떨어진 지점의 반환점을 마비 측 방향으로 최대한 빠른 걸음으로 돌아 다시 의자에 앉을 때까지 소요된 시간을 측정하는 방법으로 3 회 반복 측 정하여 평균시간을 기록하였다. ${ }^{15}$

\section{(3) 정적과 동적균형 능력 검사}

버그 균형 척도(Berg’s balance scale, BBS)는 정적균형과 동적균형 능력 을 객관적으로 평가하는 검사도구로 측정자 내 신뢰도는 $r=0.97$ 이 고, 측정자 간 신뢰도는 $r=0.99$ 로 높은 내적 타당도를 지닌다. BBS는 14 개의 항목으로 앉기, 서기, 자세 변화의 3 개의 영역을 최소 0 점에서 최대 4점으로 적용되어 총점은 56점으로 높은 점수를 기록할수록 높은 균형능력을 평가받는다. ${ }^{16}$

\section{3. 자료처리}

본 연구에서 얻은 자료는 윈도우용 SPSS version 18.0 을 이용하여 분 석하였다. 측정된 자료의 정규분포를 알아보기 위하여 샤피로 윌크 (Shapiro-Wilk) 검정을 실시하였다. 두 군 간의 성별, 마비측와 발병유 형과 같은 연구대상자들의 비율의 차이를 알아보기 위해 빈도분석 을 사용하였고 나이, 키, 몸무게, MMSE-K와 유병기간과 같은 연구대 상자들의 일반적인 특성을 파악하기 위해 기술통계를 사용하였다. 실험군과 대조군의 운동 전후에 따른 차이를 비교하기 위하여 대응 표본 t-검정(Paired t-test)을 하였고, 실험군과 대조군의 각각 운동에 따른 종속변인의 변화에 대한 군의 영향을 분석하기 위하여 공분산 분석(ANCOVA)을 실시하였다. 모든 통계학적 유의수준은 $\alpha=0.05$ 로 설정하였다.

결 과

\section{1. 집단 내 폐 기능 변화}

집단 내 노력성 폐활량(FVC)의 변화는 실험군에서만 유의한 차이가 있었고 $(\mathrm{p}<0.001), 1$ 초간 노력성 날숨량(FEV1)의 변화에서도 실험군 에서만 유의한 차이가 있었다 $(\mathrm{p}<0.01)$ (Table 2$)$.

\section{2. 집단 간 폐 기능 변화}

집단 간 노력성 폐활량 $(\mathrm{FVC})$ 의 변화에서는 실험군이 대조군보다 더 욱 효과적인 변화를 보였고( $\mathrm{p}<0.001), 1$ 초간 노력성 날숨량( $\mathrm{FEV1})$ 의 집단 간 변화에서도 실험군이 대조군보다 더욱 효과적인 변화를 보 였다 $(\mathrm{p}<0.001)$ (Table 3).

Table 2. Change of pulmonary function in group

\begin{tabular}{cccccl}
\hline & Group & Pre & Post & $\mathrm{t}$ & \multicolumn{1}{c}{$\mathrm{p}$} \\
\hline FVC (L) & Experimental & $2.43 \pm 0.90$ & $3.14 \pm 0.71$ & -5.473 & $0.000^{* *}$ \\
& Control & $2.48 \pm 0.75$ & $2.48 \pm 0.72$ & -0.183 & 0.859 \\
FEV1 (L) & Experimental & $1.98 \pm 0.73$ & $2.53 \pm 0.62$ & -5.087 & $0.001^{*}$ \\
& Control & $2.21 \pm 0.70$ & $2.20 \pm 0.72$ & 0.098 & 0.924 \\
\hline
\end{tabular}

Values are presented as mean \pm standard deviation.

FVC, Forced Vital Capacity; FEV1, Forced Expiratory Volume in 1 second. ${ }^{*} p<0.01 ;{ }^{* *} p<0.001$

Table 3. Change of pulmonary function between experimental group and control group

\begin{tabular}{cccccc}
\hline \multicolumn{1}{c}{ Group } & Pre & Post & $\mathrm{F}$ & $\mathrm{p}$ \\
\hline FVC (L) & Experimental & $2.43 \pm 0.90$ & $3.14 \pm 0.71$ & 5.915 & $0.000^{*}$ \\
& Control & $2.48 \pm 0.75$ & $2.48 \pm 0.72$ & & \\
FEV1 (L) Experimental & $1.98 \pm 0.73$ & $2.53 \pm 0.62$ & 4.619 & $0.000^{*}$ \\
& Control & $2.21 \pm 0.70$ & $2.20 \pm 0.72$ & & \\
\hline
\end{tabular}

Values are presented as mean \pm standard deviation.

FVC, Forced Vital Capacity; FEV1, Forced Expiratory Volume in 1 second. ${ }^{*} p<0.001$ 
Table 4. Change of balance ability in group

\begin{tabular}{llccrl}
\hline & \multicolumn{1}{c}{ Group } & Pre & Post & $\mathrm{t}$ & $\mathrm{p}$ \\
\hline TUG & Experimental & $16.37 \pm 6.90$ & $11.81 \pm 4.64$ & 5.388 & $0.000 * *$ \\
(sec) & Control & $15.26 \pm 4.11$ & $14.67 \pm 4.10$ & 3.155 & $0.012 *$ \\
BBS & Experimental & $43.30 \pm 5.08$ & $48.30 \pm 4.92$ & -19.365 & $0.000 * *$ \\
(score) & Control & $44.40 \pm 10.39$ & $44.90 \pm 10.47$ & -2.236 & 0.052 \\
\hline
\end{tabular}

Values are presented as mean \pm standard deviation.

TUG, Timed Up and Go Test; BBS, Berg's Balance Scale.

${ }^{*} p<0.05 ;{ }^{* *} p<0.001$.

\section{3. 집단 내 균형능력 변화}

집단 내 동적균형(TUG)의 변화는 실험군에서 유의한 차이가 있었고 $(\mathrm{p}<0.001)$, 대조군에서도 유의한 차이가 있었다 $(\mathrm{p}<0.05)$. 집단 내 정 적과 동적균형(BBS)의 변화는 실험군에서만 유의한 차이가 있었다 $(\mathrm{p}<0.001)($ Table 4$)$

\section{4. 집단 간 균형능력 변화}

집단 간 동적균형(TUG)의 변화에서는 실험군이 대조군 보다 더욱 효과적인 변화를 보였고 $(\mathrm{p}<0.001)$, 정적과 동적균형(BBS)의 변화에 서도 실험군이 대조군 보다 더욱 효과적인 변화를 보였다 $(\mathrm{p}<0.001)$ (Table 5).

\section{고 찰}

우리 몸에서 복부근육은 허리부위를 안정화시키며, 몸통조절과 몸 통의 안정성을 제공하여 인체의 자세를 유지시키는 기능을 한다.17 특 히 노력성 호기나 강한 호기 시에 복부 내압을 증가시킴으로써 가로 막을 활성화시키고 가슴내부의 공기를 외부로 배출시키는 역할을 한 다. ${ }^{18}$ 그러나 뇌졸중 환자들은 몸통 및 호흡근육 특히 복부근육의 약 화로 근 긴장도를 감소시켜 호흡능력 저하와 몸통조절의 어려움을 나타내는데, ${ }^{19}$ 본 연구에서는 위와 같은 문제점을 가지고 있는 뇌졸 중 환자를 대상으로 6 주간 주 5 일 동안 복부 심부근육 강화 운동을 실시하여 $\mathrm{FVC}, \mathrm{FEV1}$, 동적균형과 정적균형에 어떠한 영향을 미치는 지 논의하고자 한다.

McGill ${ }^{12}$ 에 의해 임상에서 흔히 사용하는 동작으로 curl-up, bird dog, side bridge, plank 등이 있는데 이러한 동작들은 몸통을 이루는 심부근육과 표층근육 간에 협응적 수축(co-contraction)을 이끌어낸 다. 그러나 본 연구에서 실시한 브레이싱 운동은 기능적으로 약화된 심부의 복부근육을 좀 더 효율적으로 개별수축(isolated contraction) 시키고강화시키는 운동방법이다.

Lee 등 4 은 만성 뇌졸중 환자를 대상으로 가로막 저항 운동과 입술 오므리기 운동을 실시한 호흡 운동군에서 $\mathrm{FVC}$ 가 운동 전. 후와 집 단 간 비교에서 모두 유의한 향상을 보였으며, $\operatorname{Kim}$ 등 20 은 뇌졸중 환
Table 5. Change of balance ability between experimental group and control group

\begin{tabular}{llcccc}
\hline & \multicolumn{1}{c}{ Group } & Pre & Post & F & p \\
\hline TUG & Experimental & $16.37 \pm 6.90$ & $11.81 \pm 4.64$ & -6.376 & $0.000 *$ \\
(sec) & Control & $15.26 \pm 4.11$ & $14.67 \pm 4.10$ & & \\
BBS & Experimental & $43.30 \pm 5.08$ & $48.30 \pm 4.92$ & 12.771 & $0.000 *$ \\
(score) & Control & $44.40 \pm 10.39$ & $44.90 \pm 10.47$ & & \\
\hline
\end{tabular}

Values are presented as mean \pm standard deviation.

TUG, Timed Up and Go Test; BBS, Berg's Balance Scale.

${ }^{*} \mathrm{p}<0.001$.

자를 대상으로 날숨근육 운동기를 이용하여 호흡 강화 운동을 중재 한 결과, 대조군에 비해 호흡 강화 운동군에서 FVC가 유의하게 증가 되었다. 그리고 Choi'는 뇌졸중으로 진단을 받은 입원 및 외래 환자에 게 복부근육 강화 운동군에서 FVC가 유의한 향상을 나타냈는데, 본 연구에서도 복부 심부근육 강화 운동을 실시한 실험군에서 $\mathrm{FVC}$ 와 $\mathrm{FEV} 1$ 는 운동 전보다 운동 후에 유의하게 개선되었다 $(\mathrm{p}<0.001)$ $(\mathrm{p}<0.01)$. 또한 집단 간 비교에서도 대조군에 비해 복부 심부근육 강 화 운동을 실시한 실험군에서 유의한 차이를 보여( $\mathrm{p}<0.001)$, 선행 연 구와 같이 호흡운동 방법에는 다소 차이가 있었지만 지지하는 결과 를 도출할 수 있었다. 그 이유로는 반복된 호흡운동으로 인하여 호흡 근육의 수축력과 근력 증가에 따른 운동학습에 의한 효과가 있는 것 으로 사료된다.21

$\mathrm{Kim}$ 등 22 은 만성요통을 가진 환자의 간병인들을 대상으로 앉은 자 세에서 복부 심부근육수축 훈련을 1-5일간 실시한 결과 5일 날부터 요통의 유의한 감소와 함께 FEV1의 향상을 볼 수 있었으며, Lee $\mathrm{L}^{21}$ 는 20 세 초반의 여학생을 대상으로 바로누운자세와 기립자세에서 복부 심부근육 수축 유무에 따른 FEV1을 측정한 결과 기립자세에서 복부 심부근육을 수축시킬 때 유의한 결과를 얻어 위 두 선행연구에서 알 수 있듯이 폐 기능을 향상시키기 위해서는 복부 심부근육 강화운동 이 필요함을 알 수 있다. Yun 등23은 독립적 보행이 가능한 뇌졸중환 자 14명을 대상으로 실험군 7명, 대조군 7명 무작위 배정하여 복합운 동과 복부 끌어 담김 조정운동을 실시한 결과 복부 근육 근활성도에 서 유의한 변화를 보였지만, 폐 기능 검사에서는 FVC에서만 통계적 으로 유의한 차이를 보였고, FEV1은 통계적으로 유의한 차이를 얻지 못하였다. 그러나 본 연구에서는 복부 심부근육인 배가로근을 6 주간 주5일 중재하여 FEV1에서 통계적으로 유의한 차이를 얻어 $(\mathrm{p}<0.001)$ 선행연구와 상반되는 결과를 도출하였는데, 그 이유로는 제한성 양 상을 보이는 뇌졸중환자에게 복부 심부근육의 강화를 통해 호흡기 능의 향상, 근육의 두께변화와 근력 향상이 복부내압의 증가와 날숨 능력의 향상으로 FEV1의 향상에 영향을 미친 것으로 해석된다.20,24

복부 심부근육 강화 운동이 정적과 동적균형능력에 어떠한 영향 을 미치는지 평가하기 위하여 TUG와 BBS 검사를 실시한 결과, 실험 
군에서 TUG와 BBS는 운동 전보다 운동 후에 유의하게 개선되었으 며( $\mathrm{p}<0.001)$, 대조군에서도 운동 후 TUG와 BBS에서 유의한 향상을 보였지만, 집단 간 비교에서는 대조군에 비해 복부 심부근육 강화 운 동을 실시한 실험군에서 유의한차이가 나타났다 $(\mathrm{p}<0.001)$. Shim 등 25 은 뇌졸중으로 인한 편마비 환자를 대상으로 몸통 안정화운동을 실 시한 중추신경발달치료군에서 TUG가 더욱 유의한 향상을 보였으 며, Shin 등 ${ }^{26}$ 이 발병 후 6 개월이 경과한 뇌졸중환자 46 명 중 중도 탈 락한 8 명을 제외한 38 명을 대상으로 몸통 안정화 운동을 중재한 결 과 실험군에서 BBS가 통계적으로 유의한 결과를 보였다. 그리고 Lee 등 ${ }^{27}$ 은 뇌졸중 환자에게 몸통 안정화 운동과 몸통 저항운동을 중재 한 집단에서 BBS가 통계적으로 유의한 차이를 보여 본 연구 결과를 지지하고 있는데, 이러한 결과는 본 연구의 운동방법처럼 직접적인 몸통의 근력증가를 통해서 정적과 동적균형능력이 향상됨을 알 수 있으며, 본 연구의 운동방법이 균형능력을 향상시키는 데 효과적임 을 재확인할 수 있다.

이와 같이 복부 심부근육 강화 운동은 폐 기능과 균형능력 향상 에 효과가 있음을 확인할 수 있었으며, 뇌졸중으로 몸통 및 호흡근육 특히 복부근육의 약화를 보이는 대상자를 복부 심부근육의 근력의 향상이 폐 기능까지도 향상시키는 기능적인 접근방법으로 반복적 운동학습을 통한 결과라고 사료된다. 그러므로 몸통 및 호흡근육 특 히 복부근육의 약화로 근 긴장도를 감소시켜 호흡능력 저하와 몸통 조절의 어려움을 겪는 뇌졸중 환자를 대상으로 복부 심부근육 강화 운동에 대한 앞으로의 연구가 더욱 필요할 것이다.

본 연구의 제한점으로는 대상자 수가 상대적으로 적고 이를 뇌졸 중환자에게 일반화하여 해석하기에는 어려움이 있으며 운동이 필요 한 뇌졸중환자들로서 다른 활동이나 운동을 통제하지 못하였기에 연구결과에 영향을 미칠 수 있다는 점이다.

\section{ACKNOWLEDGEMENTS}

The Research has been conducted by the Research Grant of Sehan University in 2015.

\section{REFERENCES}

1. Sutbeyaz ST, Koseoglu F, Inan L et al. Respiratory muscle training improves cardiopulmonary function and exercise tolerance in subjects with subacute stroke: A randomized controlled trial. Clin Rehabil. 2010;24(3):240-50.

2. Britto RR, Rezende NR, Marinho KC et al. Inspiratory muscular training in chronic stroke survivors: A randomized controlled trial. Arch Phys Med Rehabil. 2011;92(2):184-90.

3. Kim CB, Choi JD. Comparison of pulmonary and gait function in sub- acute or chronic stroke patients and healthy subjects. J Kor Phy Ther. 2011;23(5):23-8.

4. Lee JH, Kwon YJ, Kim K. The effect of chest expansion and pulmonary function of stroke patients after breathing exercise. J Kor Phy Ther. 2009;21(3):25-32

5. Cameron MH, Monroe LG. Physical rehabilitation evidence-based examination, evaluation, and intervention. Philadelphia, Elsevier Health Sciences, 2007:689-732.

6. Hodges PW, Gurfinkel VS, Brumagne S et al. Coexistence of stability and mobility in postural control: evidence from postural compensation for respiration. Exp Brain Res. 2002;144(3):293-302.

7. Chae JB, Lee MH. Effect of spinal stabilization with visual feedback on the balance of chronic stroke patients. J Phys Ther Sci. 2011; 23(2):22931.

8. Seo DK, Kwon OS, Kim JH et al. The effect of trunk stabilization exercise on the thickness of the deep abdominal muscles and balance in patients with chronic stroke. J Phys Ther Sci. 2012;24(2):181-5.

9. Choi YC. The effects of trunk stabilization exercise on deep abdominal muscles thickness and pulmonary function in chronic stroke patients. Yongin University Dissertation of Master's Degree. 2013.

10. Yoon JW. The effect of core stability exercise for inspiratory competence in patient with stroke. Yongin University Dissertation of Master's Degree. 2013.

11. Jung JH, Shim JM, Kwon HY et al. Effects of Abdominal Stimulation during Inspiratory Muscle Training on Respiratory Function of Chronic Stroke Patients. J Phys Ther Sci. 2014;26(1):73-6.

12. McGill SM. Low back stability: From formal description to issues for performance and rehabilitation. Exerc Sport Sci Rev. 2001;29(1):26-31.

13. Grenier SG, McGill SM. Quantification of lumbar stability by using 2 different abdominal activation strategies. Arch Phys Med Rehabil. 2007;88(1):54-62.

14. Jeon CB. Effects of a trunk stabilization exercise on the thickness of the deep abdominal muscles and balance in hemiplegic patients. Daegu University Dissertation of Doctorate Degree. 2013.

15. Podsiadlo D, Richardson S. The timed "Up \& Go": A test of basic functional mobility for frail elderly persons. J Am Geriatr Soc. 1991;39(2): 142-8.

16. Berg K, Wood-Dauphinee S, Williams JI. The Balance Scale: Reliability assessment with elderly residents and patients with an acute stroke. Scand J Rehabil Med. 1995;27(1):27-36.

17. Neumann P, Gill V. Pelvic floor and abdominal muscle interaction: EMG activity and intra-abdominal pressure. Int Urogynecol J Pelvic Floor Dysfunct. 2002;13(2):125-32.

18. Reid WD, Dechman G. Considerations when testing and training the respiratory muscles. Phys Ther. 1995;75(11):971-82.

19. Lanini B, Bianchi R, Romagnoli I et al. Chest wall kinematics in patients with hemiplegia. Am J Respir Crit Care Med. 2003;168(1):109-13.

20. Kim MH, Lee WH, Yun MJ. The effects on respiratory strength training on respiratory function and trunk control in patient with stroke. J Kor Phy Ther. 2012;24(5):340-7.

21. Lee BK. The effect of the forced pulmonary function of young female, by changes in lung function related to postures and by transverse abdominis activation in standing position. J Korean Soc Phys Med. 2012;7(3): 267-74. 
22. Kim KS, Kwon OY, Yi CH. Effect of abdominal drawing-In maneuver on peak expiratory flow, forced expiratory volume in 1 second and pain during forced expiratory pulmonary function test in patients with chronic low back pain. Phys Ther Korea. 2009;16(1):10-7.

23. Yun JH, Kim TS, Lee BK. The effects of combined complex exercise with abdominal drawing-in maneuver on expiratory abdominal muscles activation and forced pulmonary function for post stroke patients. J Korean Soc Phys Med. 2013;8(4):513-23.

24. Song JM, Kim SM. The effect of aquatic exercise on the improvement of physical and pulmonary function after stroke. J Kor Phy Ther. 2009;
21(2):15-22.

25. Shim HB, Cho HY, Choi WH. Effects of the trunk stabilization exercise on muscle activity in lumbar region and balance in the patients with hemiplegia. J Kor Phy Ther. 2014;26(1)33-40.

26. Shin WS, Kim CY, Lee DY et al. The effects of trunk stability exercise on dynamic balance in the persons with chronic stroke. Journal of the Korea Academia-Industrial cooperation Society. 2009;10(9):2509-15.

27. Lee JY, Park JS, Lee DH et al. Effect of the trunk muscle stabilization training on balance for chronic stroke patients. Journal of the Korea Academia-Industrial cooperation Society. 2012;13(3):1212-9. 